\title{
DOMESTIC URBAN SPACE: REDEFINITION FOR THE POOR
}

Alshimaa Abolmakarem Farag

\begin{abstract}
The provision of adequate home is one of the most decent living needs of human beings. Therefore, the state has built several residential projects in order to provide proper housing especially for the poor citizens in view of their limited financial situation. Domestic urban spaces have not received the appropriate attention despite its social and economic importance for this category. Decision makers who are usually affected by international theories and literature definitions deal with these spaces in curious vision that is incompatible with the spirit of the place and the requirements of ordinary people and their living style. A comparison between theory, literature, and theoretical definitions of such spaces, and the users dealings with the urban space in practice, reveals the difference between theoretical concept and rei practice. This comparison emphasizes the importance of redefining the domestic urban space such that the performance of an urban designer should meet the real needs. The objective of the comparison is to prove the differences between the local reality and theory derived from communities characterized by different cultural traits. The author follows the deductive method to prove the differences in the definition of "Domestic Urban space". This research is concerned with external urban spaces close to homes in residential areas and known as "Domestic Urban Spaces", especially which is designed for poor people.
\end{abstract}

